\title{
Electrochemical machining - state of the art and direction of development
}

\author{
Obróbka elektrochemiczna - stan badań i kierunki rozwoju
}

ADAM RUSZAJ *

Electrochemical machining process (ECM) can be applied for efficient shaping advanced materials conducting electrical current which are difficult or impossible for machining using conventional methods. In electrochemical machining workpiece is anode and material is removed as a result of electrochemical reactions "atom by atom" without mechanical forces. This mechanism of material removal make it possible to obtain high quality of machined surface layer with uniform properties. The very important advantage of ECM process is also the fact that there is not electrode - tool wear because the equivalent reaction to anodic dissolution is hydrogen generation on cathode surface and hydrogen can be easy removed form interelectrode gap by electrolyte flow. Because of this advantages ECM process is widely applied in space, aircraft, car and electromechanical industry and research stimulating ECM development are carried out.

KEYWORDS: ECM, pulseECM, ECM-CNC, microECM, wireECM

\section{General characteristics of the ECM process}

The machining allowance in the ECM process is removed as a result of electrochemical reactions taking place on the surface of the workpiece, which is the anode (fig. 1). The inter-electrode space is filled with a flowing electrolyte. Atoms of the workpiece, under the influence of electric field, undergo ionization and diffuse into the inter-electrode gap, where they enter further reactions. The equivalent reaction that takes place at the surface of the cathode is deionization of hydrogen ions. An electric current flows between the anode and the cathode, and heat is released according to Joule's law. The reaction products (e.g. hydroxides and hydrogen) and heat are removed by the electrolyte flowing through the gap. Therefore, the concentration of hydrogen and dissolution products as well as temperature change in direction of the electrolyte flow, which significantly affects the electrolyte conductivity distribution and thickness of the inter-electrode gap - see equations (1) and (2) [1-5].

The dissolution process follows the laws of Ohm and Faraday. On this basis, the machining efficiency and the thickness of the inter-electrode gap can be determined. For the case from fig. 1 - assuming that the process is steady, and the electrolyte properties are constant in the

\footnotetext{
* Prof. dr hab. inż. Adam Ruszaj (aruszaj@mech.pk.edu.pl) Instytut Technologii Maszyn i Automatyzacji Produkcji, Wydział Mechaniczny Politechniki Krakowskiej oraz Instytut Techniczny Państwowej Wyższej Szkoły Zawodowej w Nowym Sączu
}

DOI: https://doi.org/10.17814/mechanik.2017.12.188

inter-electrode space - following formula is obtained [1, 5]:

$$
S_{\mathrm{u}}=\frac{\eta k_{\mathrm{v}} \kappa(U-E)}{v_{\mathrm{f}}}
$$

where: $S_{u}$ - thickness of the inter-electrode gap in the steady state of the process, $\eta$-current efficiency of the dissolution process, $k_{v}$ - electrochemical equivalent of the material processed, $K$ - electrical conductivity of the electrolyte, $E$ - sum of the decreases in the electrical potential at the electrode and electrolyte interface, $U$ inter-electrode voltage, $v_{f}$ - feedrate of the working electrode.

The electrical conductivity of the electrolyte, in general case, can be calculated from the following relationship [1-5]:

$$
\kappa=\kappa_{0}(1+\alpha \Delta T)\left(1-C_{H}\right)^{3 / 2}
$$

where: $\kappa$ - specific electrolyte conductivity at selected point of inter-electrode space, $\kappa_{0}$ - specific electrolyte conductivity at the inlet to the machining area, $\alpha$ temperature electrolyte conductivity coefficient, $C_{H}$ hydrogen volume concentration.

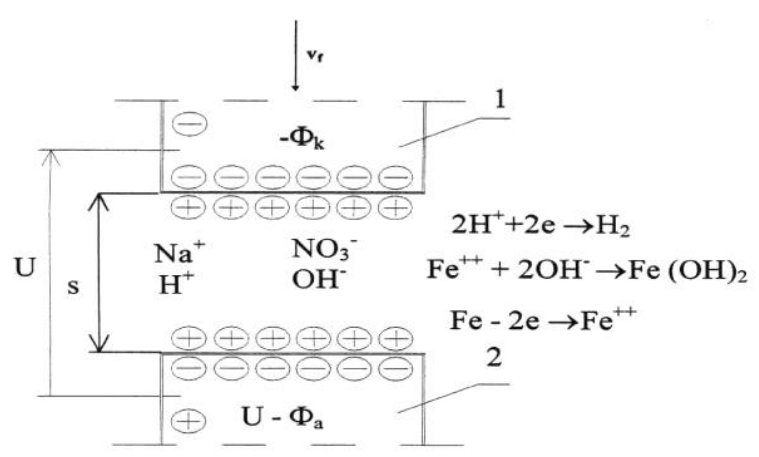

Fig. 1. Simplified diagram of the inter-electrode area in the electrochemical machining in the aqueous solution of $\mathrm{NaNO}_{3}$; $\Phi_{a}, \Phi_{k}$ - electrode potentials, $U$ - inter-electrode voltage, $v_{f}$ working electrode feedrate, $S$ - inter-electrode gap thickness [5]

Phenomena occurring in the inter-electrode gap determine the basic advantages of the ECM process [15], such as:

- possibility of efficient machining of electrically conductive materials, regardless of their mechanical properties, difficult or impossible to process using classical methods; 
- possibility of obtaining a good quality surface layer and a small surface roughness, because the material is removed with the smallest possible portions - atoms, and to remove the allowance, mechanical forces introducing changes in the surface layer are not needed; of course, even very high forces act on the workpiece and working electrode when processing large surfaces due to electrolyte pressure flowing through the machining area; - no wear of the working electrode; material is not removed during the process from the surface of the tool working electrode.

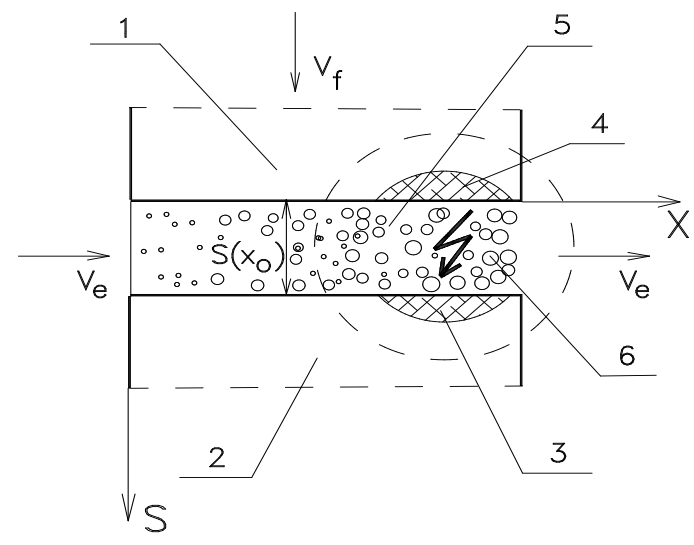

Fig. 2. Diagram of damage to the electrode as a result of electrical discharges: 1 - working electrode; 2 - workpiece; 3 material removed from the machined surface as a result of an electric discharge; 4 - material removed from the surface of working electrode as a result of an electric discharge; 5 - area of the inter-electrode gap, in which the critical condition occurred; 6 - gas bubbles; $v_{f}$ - feedrate of the working electrode; $v_{e}$ - electrolyte flow rate [5]

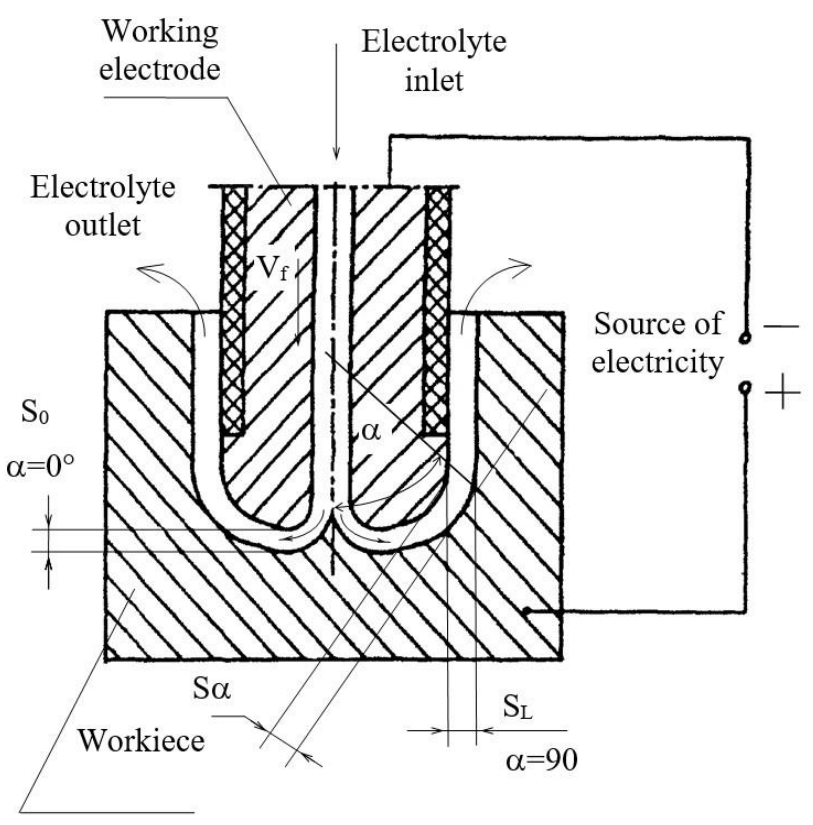

Fig. 3. Scheme of a 3D curved surface drilling (e.g. die working cavity, mold cavities or mold). Values used in practice, sometimes exceeding 10,000 A, cause an intensive release of hydrogen and heat. To maintain the electrolyte temperature and hydrogen volume concentration, the electrolyte flow rate may be as high as $20 \mathrm{~m} / \mathrm{s}$ [5]. Explanations: $\alpha$ - angle of the machined surface outline; $S_{0}, S_{\alpha}, S_{L}$ - inter-electrode gap thickness respectively for: $\alpha=0^{\circ}$ point with outline angle $\alpha, \alpha=$ $90^{\circ}$
The basic condition for gaining of these benefits is uniform and stable electrolyte flow through the interelectrode gap and possibly a small change in the electrolyte properties, and in particular its specific electrical conductivity, the value of which depends, among others, on the temperature and volume concentration of hydrogen. The electrolyte flow conditions should guarantee its even distribution on the machined surface, without any stagnation zones, circulation or cavitation areas. In addition, the flow rate should be selected so that the temperature and hydrogen volume concentration do not exceed the critical values ( $T_{k r} \approx 60-70{ }^{\circ} \mathrm{C}, C_{H, k r} \approx 70 \div 75 \%$ ). Otherwise, electrical discharges will appear in the gap, damaging both electrodes and causing the process to be interrupted (fig. 2) $[1-5]$

From this simplified description, basic problems related to modeling and computer simulation of the ECM process emerge. As a result of modeling, spatial distributions of all discussed sizes are obtained, in particular, the distribution of inter-electrode gap thickness is important, necessary to determine the shape and dimensions of the workpiece surface for a given electrode (so-called simple task) or to adjust the working electrode in order to obtain a given machined surface (so-called reverse task). A necessary condition for the practical use of mathematical modeling and computer simulation is a satisfactory agreement of their results with those of experiments. The described phenomena also indicate that the ECM process is characterized by relatively large randomness, which hinders its automation. In order to reduce the randomness of the process and uniform the electrolyte properties especially in the machining of complex 3D surfaces (fig. 3) - the following actions are undertaken [e.g. 1-11, 18]: - machining of complex free surfaces is accomplished even in three stages, which ensure successively high efficiency and high dimensional accuracy and surface quality;

- in the inter-electrode space, homogeneous conditions are ensured (as low as possible variability of temperature and hydrogen volume concentration), which increases the accuracy of mathematical modeling and computer simulation and allows to obtain the required machining accuracy and high quality of the machined surface.

In practice, fulfillment of the second of these conditions is achieved due to the use of:

- mixture of electrolyte with gas $\left(\mathrm{N}_{2}, \mathrm{CO}_{2}\right)$ - the mixture is prepared before entering the processing area; recently, this technological variant is rarely used - it is displaced by pulse machining;

- additional relative movements of electrodes, e.g. electrode vibrations (anodes, cathodes) - electrode vibrations cause mixing of the electrolyte in the gap; ultrasonic vibrations may be helpful;

- such pulse voltage values (often coupled with vibrations or electrode oscillations), pulse voltage time and time break between pulses (or pulse packets) that the heat and reaction products generated during the voltage pulse are completely removed by the flowing electrolyte during the interval between pulses;

- universal working electrodes with a simple shape and surface smaller than the machined surface, characterized by a special kinematics - in this case, the shape of the workpiece is obtained as a result of mapping the trajectory of relative movement of electrodes (in the ECM drill, the shape of the workpiece 
is obtained as a result of mapping the shape and dimensions of the corrected working electrode);

- combinations of the above cases.

Next, the activities that allowed for greater uniformity of the fluid properties (electrolyte + reaction products) were demonstrated, thus simplifying mathematical modeling and improving the accuracy of computer simulation and actual machining. It should be emphasized that the adopted simplifications also limit the randomness of the ECM process and make it more susceptible to automation.

\section{Electrochemical drilling}

The diagram of electrode vibrations in two axes is shown in fig. 4 [10]. For this case, a computer-aided design system for the technological process was developed, which includes packages for mathematical modeling of the process and its computer simulation. The system has been verified experimentally for the following parameters:

- inter-electrode voltage $15 \mathrm{~V}$

- electrolyte $15 \% \mathrm{NaNO}_{3}$,

- electrolyte efficiency of $2 \mathrm{dm}^{3} / \mathrm{min}$,

- electrolyte temperature $T=293 \mathrm{~K}$,

- electrode feedrate $v_{f}=1 \mathrm{~mm} / \mathrm{min}$,

- two variants of the working electrode vibrations: in direction of the electrode's movement (vibrations with an amplitude $A=0.1 \mathrm{~mm}$ and frequency $f=30 \mathrm{~Hz}$ ) and in the direction perpendicular to this (vibrations with an amplitude of $A=0.05 \mathrm{~mm}$ and frequency $f=60 \mathrm{~Hz}$ ) .

Based on the analysis of results from the computer simulation and their comparison with the test results, it was found that the use of vibrations of the working electrode in two axes homogenizes the electrolyte properties in the machining area, which authorizes modeling and simulation with simplifying assumptions. The compliance of the measurement results and simulations is satisfactory. Similar results were obtained in the case of modeling and computer simulation of ECM drills of rotary surfaces with different variants of vibrating motion: vibrations in the direction of electrode movement and torsional vibrations around the axis of rotation [11]. The following parameters were used in the verification tests: inter-electrode voltage $U=15 \mathrm{~V}$, electrolyte $15 \%$ $\mathrm{NaNO}_{3}$ with temperature $T=293 \mathrm{~K}$ and efficiency $Q=3$ $\mathrm{dm}^{3} / \mathrm{min}$, pressure at the inlet to the machining area $p=$ $0.1 \mathrm{MPa}$, thickness of the initial gap $S_{0}=0.2 \mathrm{~mm}$. The kinematic parameters were as follows: rotational speed of the electrode $n=800 \div 1600 \mathrm{rpm}$, vibration amplitude $A$ $=0.1 \mathrm{~mm}$, vibration frequency $f=30$ or $60 \mathrm{~Hz}$. After comparing the results of computer simulation with the test results, it was found that due to the introduction of the relative movement of electrodes (rotational motion, vibrations) in the analyzed case, a satisfactory match of these results was obtained.

Electrochemical drilling is widely used in the aviation and aerospace industry. The basic elements of aircraft engines are turbines, that are elements containing properly shaped blades. The exhaust gases hit the blades and put the turbine in a rotating motion. So far, each of the aircraft engine blades was separately manufactured (electrochemically), and then the finished blades were deposited in special hollows (locks) around the circumference of the turbine ring. Making locks in the ring and negatives of the lock on the grip parts of the blades and the assembly of the blades are very difficult and labor-intensive operations. For this reason, the blades are increasingly made electrochemically directly on the turbine ring - such a turbine made as one part is called a blisk (bladed disk). The advantages of such solution are obvious (fig. 5 and fig. 6): compactness, smaller dimensions, higher rigidity and overall strength, possibility of obtaining higher revolutions, longer intervals between inspections, etc. [12-16].

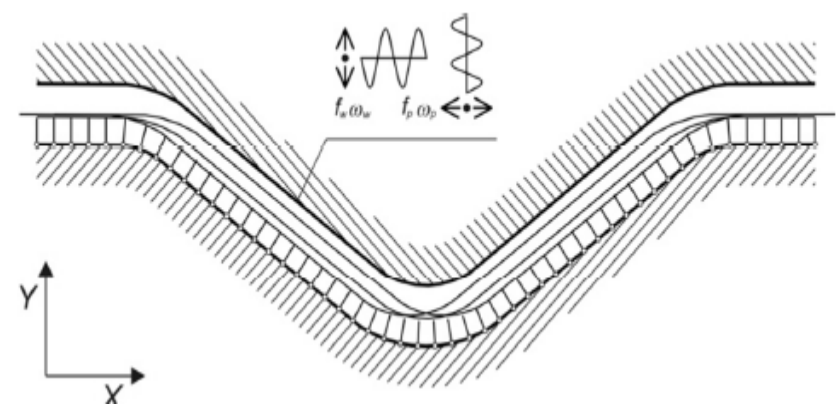

Fig. 4. Diagram of electrochemical drilling with electrode vibrating in two axes [10]

Electrochemical machining - as a very efficient method allowing to obtain a good surface quality - is used in the process of producing turbine blades of airflow engines. The ECM does not introduce changes in the surface layer that can be observed on surfaces after machining or electro-erosion machining.

Currently, machining of aerospace elements (also blisks) uses electrochemical pulse treatment with the vibrating motion of electrodes. As the electrode approaches the machined surface, a pulse packet is generated, whereas when the electrode moves away from the work surface, the products of electrochemical reactions and heat are removed outside the machined area [15]. In special cases, the machining is carried out in a pressure chamber [16] with throttling of the electrolyte outflow. As a result, electrolyte flow through the processing area is stable and critical conditions are rare. In addition, at the increased pressure in the machining zone, the volume concentration of hydrogen is smaller. This is important during machining of large precision components, carried out with high current density - in the order of $50 \div 200 \mathrm{~A} / \mathrm{cm}^{2}$, which corresponds to the current intensity of up to several thousand amperes. All of these activities are conducive to reducing the randomness of the process and improving the accuracy of processing and the quality of the surface layer. Examples of monolithic turbines generated by ECM are shown in fig. 5 and fig. 6, and examples of its other applications - in fig. 7 .

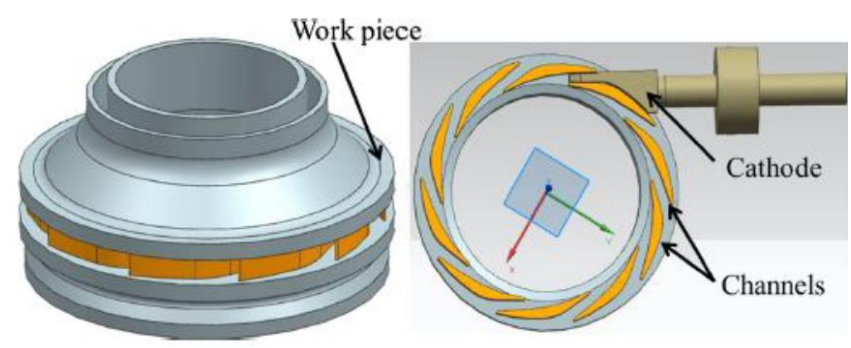

Fig. 5. Scheme of the monolithic rotor machining [12] 


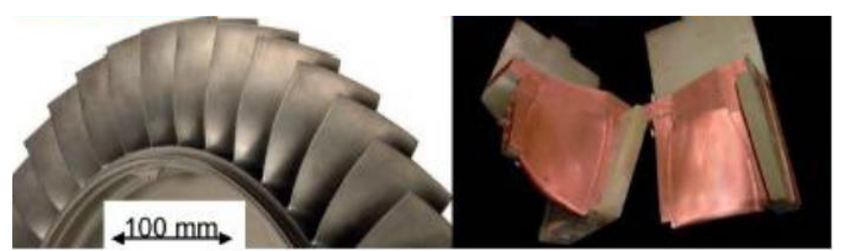

Fig. 6. Monolithic low-pressure turbine, made of Ti6Al4V (left), and electrodes, which were used to make channels between the blades (right) [16]
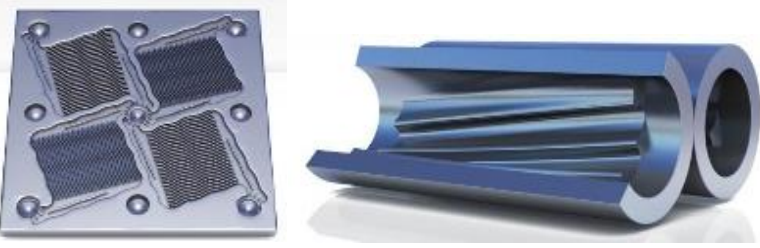

Fig. 7. Examples of elements made during the PECM drilling operation: chemical reactor plate with dimensions $30 \times 30 \mathrm{~mm}$, used in heat exchangers (left), and pump or high-pressure mixer element with a ratio of length to diameter of 100 (right) practically impossible to produce by conventional methods (source: http://electrochemicalmachining.com)

Summing up this part of the considerations, it can be concluded that due to the modification of the classic drilling process - by introducing vibrations, rotational movement of electrodes (in rotary surface processing) or pulsed voltage (PECM) - and machining in pressure chambers, more uniform dissolution conditions and electrolyte flow stabilization are obtained along with the possibility of implementing the process in stages, in which the parameters are subsequently optimized for reasons of efficiency, accuracy and surface quality. In addition, mathematical modeling and computer simulations are simplified, but their results do not differ significantly from those of experimental studies. On the other hand, it contributes to improving the quality of the workpieces and randomness reduction of the machining process, which in most cases becomes possible to automate.

\section{Electrochemical machining using universal electrodes}

In this case, the universal working electrode and the workpiece perform relative motion - shape of the machined surface is obtained as a result of mapping the trajectory of this relative motion in the workpiece. There are two cases here:

- electrochemical machining - ECGM (fig. 8),

- electrochemical milling with rotational movement of the electrode (fig. 9) or chipping - without rotation. In both cases, volume of the treatment area is small and intensively flushed with electrolyte, which justifies the assumption that the machined area has uniform and constant properties in mathematical modeling and computer simulation. With this assumption, mathematical modeling and computer simulation are easier and the obtained results satisfactorily coincide with the results of experimental research. Also in the case under consideration, the machining process is more stable than drilling. In addition, often during milling or chipping, the working electrode is moved above the machined surface, which excludes the occurrence of short circuits or contact (collision) of electrodes. This creates ideal conditions for automation - systems for such machining are marked as ECM-CNC.
Mathematical modeling, computer simulations and experimental tests of the ECGM process [17] allow to state that it allows the machining of a specific class of products with complex 3D shapes. The results of modeling and computer simulation are sufficiently in line with the results of experimental studies. The randomness of the process is much smaller as compared to the classic drilling, therefore the process can be automated.

Fig. 9 shows a schematic diagram of electrochemical milling using rotating electrode moving along a special trajectory. In some cases, the electrode does not perform rotational motion - this operation is called ECM chipping. Universal electrodes can have any shape, but usually spherical roll electrodes are used in the macromachining, while in micro-machining - flat cylindrical electrodes $[5,7-9,18,20,23]$. The ECM machining with universal electrodes is a stable process and convenient for mathematical modeling, computer simulation and automation, but it has one major disadvantage, namely very low efficiency. This type of machining is used for special operations, such as the manufacture of thinwalled elements, treatment of apertures or pockets [23] and finishing operations (smoothing) of the surface after coarse classical milling or electro-discharge machining (fig. 15 and fig. 16) [19].

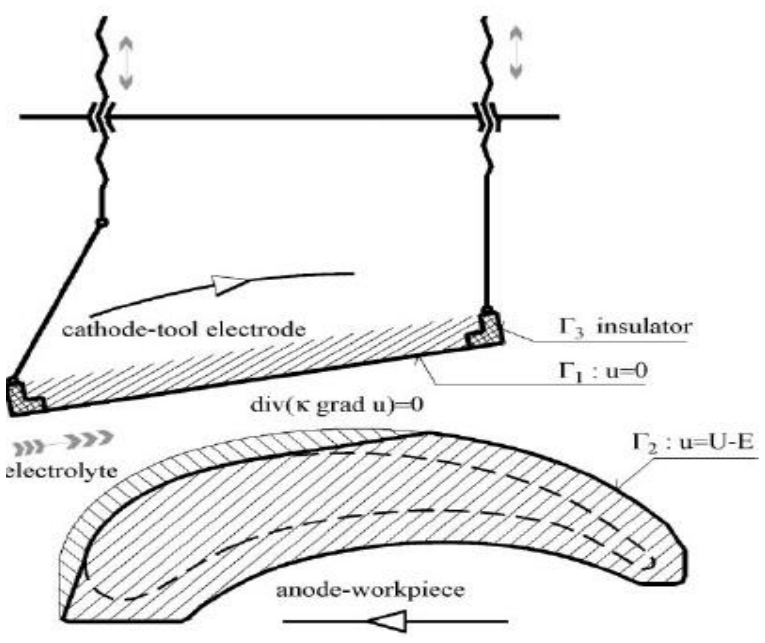

Fig. 8. The ECGM process diagram - shape of the workpiece is obtained by mapping the trajectory of the relative motion of a flat working electrode [17]

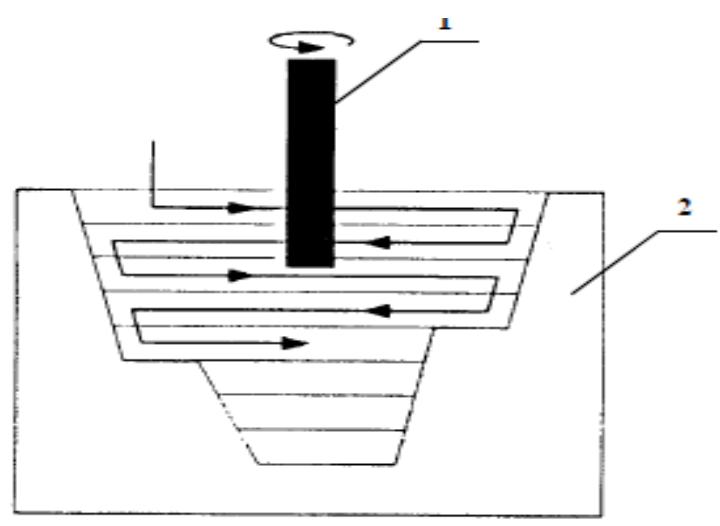

Fig. 9. Diagram of electrochemical milling using a universal cylindrical electrode (1 - cylindrical electrode, 2 - workpiece) [5]

The universal working electrode can have any shape, however, spherical or flat cylindrical electrodes are most 
commonly used. The electrolyte is supplied to the machining area in a forced manner - through the hole in the electrode (fig. 10 - macro-machining) - either the electrode and the processing area are electrolyte plated through the outer nozzle (fig. 11 - usually micromachining).

Selecting the machining parameters accordingly, tracks (waviness, craters after discharges) after roughing with milling or electro-discharge machining can be removed. For example, the surface waveforms after milling the free 3D surface with a ball mill with a radius of $R=5 \mathrm{~mm}$, amounting to $0.1 \mathrm{~mm}$, were reduced to practically zero, i.e. to the surface roughness scale $(R a \approx$ $2 \mu \mathrm{m})$, which was achieved by smoothing under the following conditions: $U=16 \mathrm{~V}, v_{p}=42 \mathrm{~mm} / \mathrm{min}, S_{0}=0.2$ $\mathrm{mm}$, working electrode with radius $R=9 \mathrm{~mm}$, processing time $t=45 \mathrm{~min}$, electrolyte $-15 \%$ aqueous $\mathrm{NaNO}_{3}$ solution [18].

Studies on universal electrodes have been described, among others in $[5,7,8,18]$. This work presents a mathematical model, results of computer simulations and results of experimental research in the field of shaping elements and smoothing the surface, above all with a spherical electrode. These results allowed to develop a comprehensive system - used for mathematical modeling and computer simulation as well as computer-aided design of the technological process - coupled with ECM$\mathrm{CNC}$ electrochemical machine, on which this process is carried out automatically. The system includes [5]:

- A - subsystem of computer-aided design of the technological process, including: a computer technology database with software supporting selection of processing conditions; software for computer simulation of the machining process based on a mathematical model; software supporting the design of the working electrode trajectory and optimization of machining conditions in order to obtain the assumed shape of the workpiece and required properties of the surface layer; software for automatic generation of the electrochemical machine control program EOCA 40; AutoCAD and PROENGINEER systems;

- B - subsystem of the machining process, including the PRONUM 640 FC control system and the EOCA 40 machine tool;

- C - subsystem managing the cooperation of subsystems A and B and the flow of information within the system.

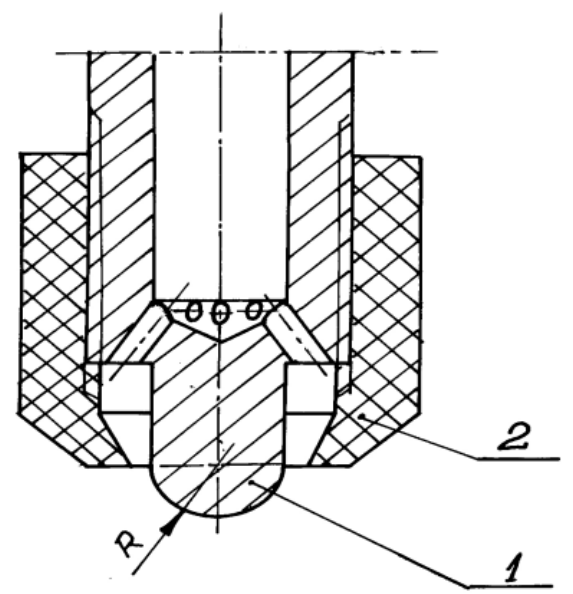

Fig. 10. Spherical ball shaped electrode used in ECM shaping of macroelements ( $R$ - radius of working electrode, 1 - working electrode, 2 - nozzle changing the direction of electrolyte flow) [5]
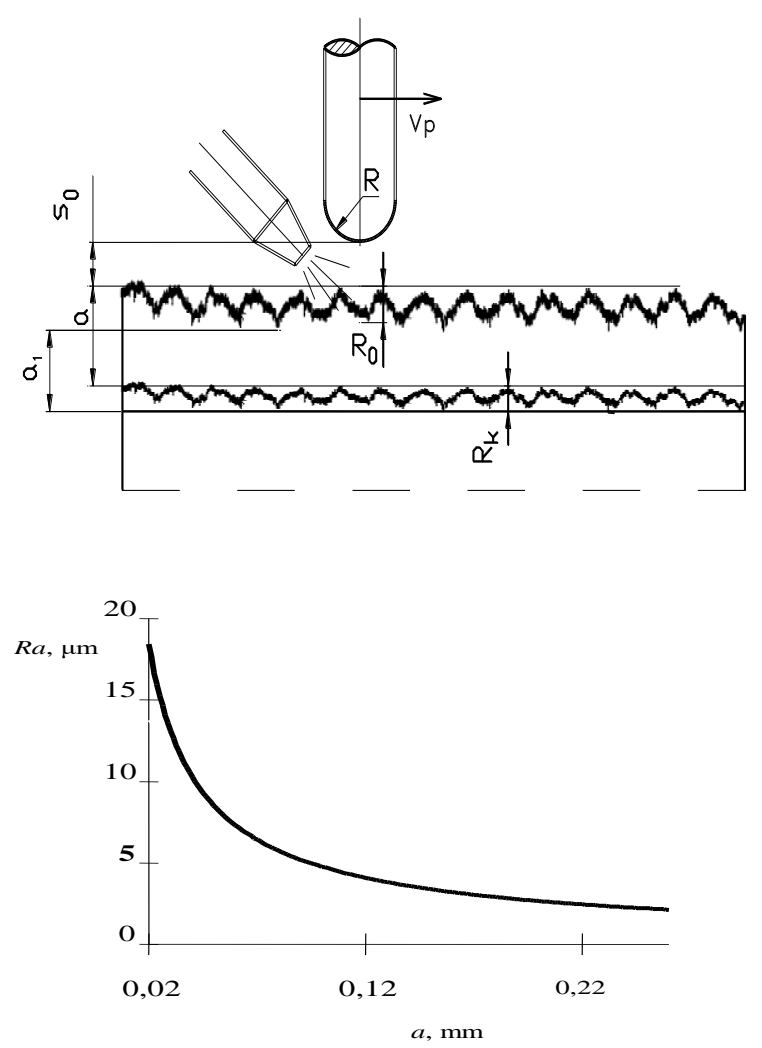

Fig. 11. Scheme of smoothing the surface with a universal spherical-shaped electrode (at the top) and the relation $R a=$ $\mathrm{f}(\mathrm{a})$ (bottom); $v_{p}$ - feedrate of universal working electrode movement over the workpiece (smoothed), - allowance removed from the uneven tops, $a_{1}$ - finishing allowance removed from the uneven bottom, $R$ - working electrode radius, $R_{0}$ - uneveness surface height before smoothing, $R_{k}$ unevenness height after smoothing, $R a$ - surface roughness [5, $7,8]$

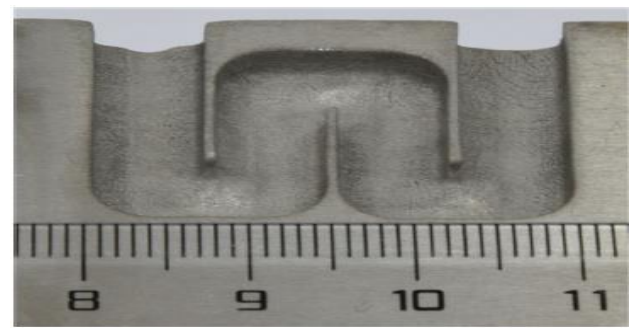

Fig. 12. Thin-walled element made by electrochemical milling using the electrode shown in fig. 13 [23]

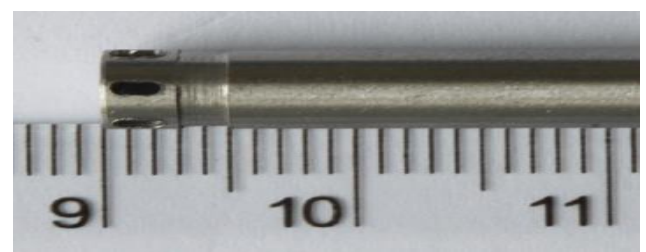

Fig. 13. Electrode for milling a thin-walled structure shown in fig. 12. The electrolyte is supplied to the machining area through holes made in the side surface - cylindrical, the electrolyte allowance is also removed by this surface [23]

\section{Electrochemical micro-machining}

Electrochemical machining of microelements or microstructures is usually carried out in the following operations: drilling (without rotating electrode), drilling (with electrode rotation), milling (with electrode rotation) and chipping (without rotating electrode) [19-26]. In the 
case of micro-machining $(d<<1 \mathrm{~mm})$, performance and positioning of the working electrode pose a serious problem. For this reason, working electrodes are usually made on the same machine tool, on which microelements are produced [22].

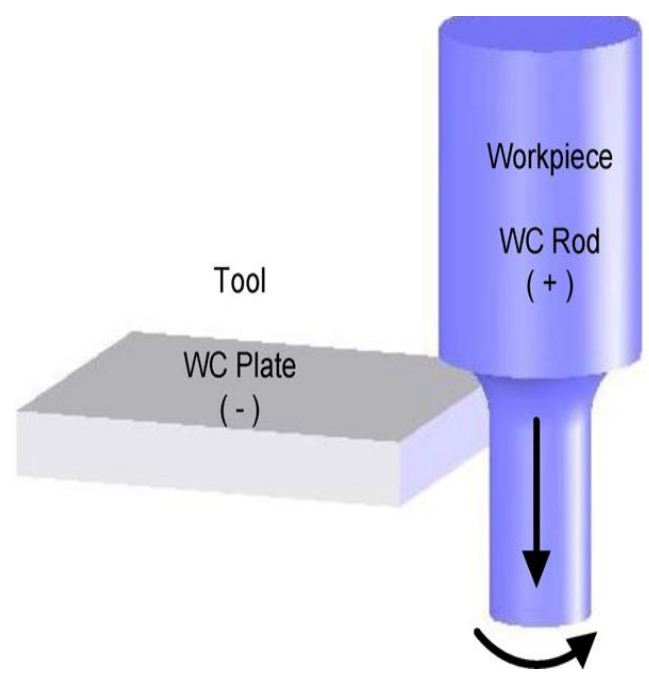

Fig. 14. Diagram of machining a working electrode for common drilling or drilling the micro-holes and for milling the 3D microstructures [22]

Applying the PECM and the electrode manufactured in the manner shown in fig. 14, holes with a diameter of 48 $\mu \mathrm{m}$ (at the electrode input) and $42 \mu \mathrm{m}$ (at the electrode output) were made in the WC-Co plate with a thickness of $200 \mu \mathrm{m}$. The electrolyte was $0.5 \mathrm{M} \mathrm{NaNO}_{3}+0.2 \mathrm{M}$ $\mathrm{H}_{2} \mathrm{SO}_{4}$, and the process parameters were as follows: inter-electrode gap thickness $3 \div 5 \mu \mathrm{m}, 9 \mathrm{~V}$ voltage pulses, pulse time $100 \mathrm{~ns}$, pulse gap $1 \mu \mathrm{s}$, electrode feedrate $0.1 \mu \mathrm{m} / \mathrm{s}$ [22]. Also in the PECM process, but with a working electrode in the form of a $10 \mu \mathrm{m}$ platinum wire, $50 \mathrm{~ns}$ pulse time, $1.6 \mathrm{~V}$ pulse voltage and $2 \mathrm{MHz}$ pulse frequency, 3D structures of $<30 \mu \mathrm{m}$ were made the smallest spatial structure was $5 \times 10 \times 12 \mu \mathrm{m}$ [24]. Of course, the larger the dimensions of designed holes and micro-shapes, the easier it is to form them. Examples of microstructures produced on an industrial scale are shown in figs. 15-17.

Microelements or microstructures are more and more often produced using the WECM wire cutting method, however the basic problem here is the removal of dissolving products, hydrogen and heat from the machined area (fig. 18). The solution to this problem is to ensure relative movements of the wire (cathode) and the workpiece (anode) (fig. 19) and the use of wire with a special side surface structure (fig. 21).

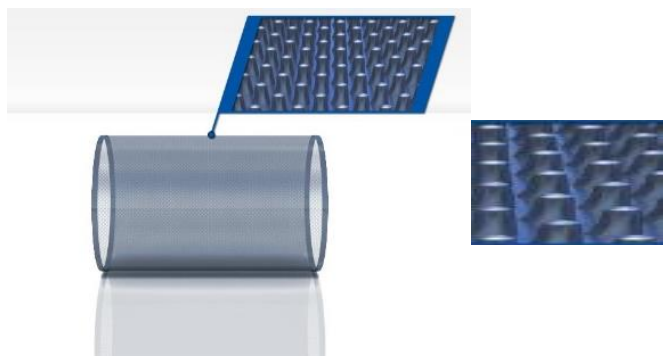

Fig. 15. Cylindrical element (left) for the production of perforated elements with a special microstructure (right) (source: http: // electrochemicalmachining.com)

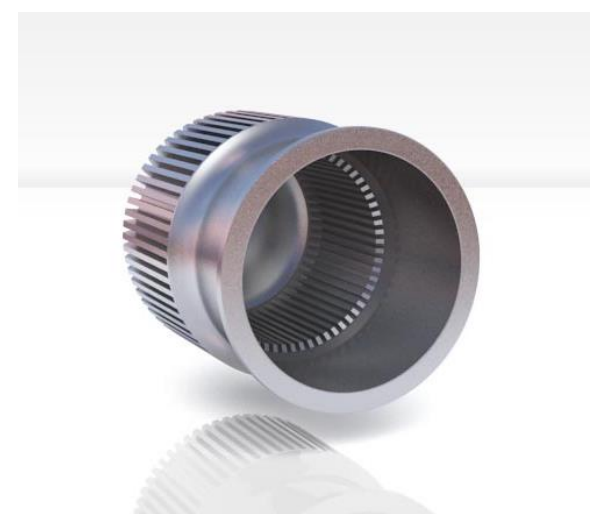

Fig. 16. Element made of nickel alloy with 90 inner ribs, $600 \mu \mathrm{m}$ wide (source: http:// electrochemicalmachining.com)

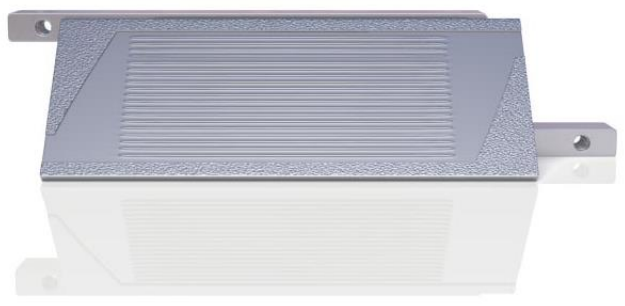

Fig. 17. Plate of heat exchanger with micro-channels with dimensions of $800 \times 400 \mu \mathrm{m}$, made of nickel alloy (source: http://electrochemicalmachining.com)

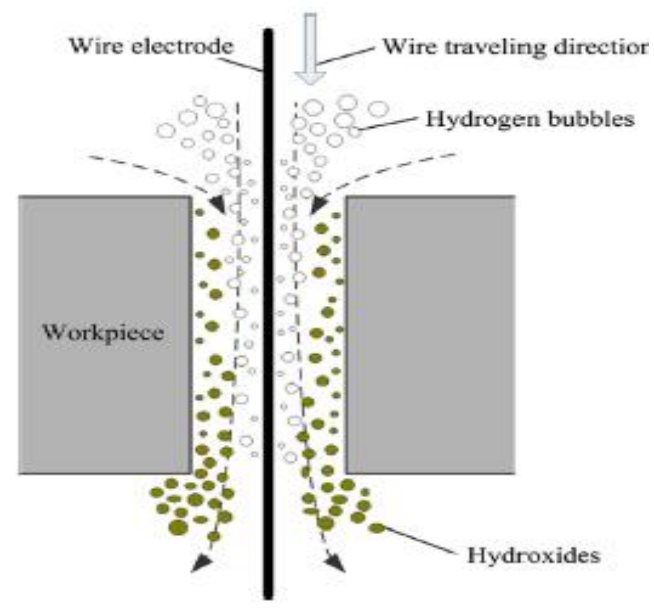

Fig. 18. Diagram of the cutting area in the case of WECM [27]

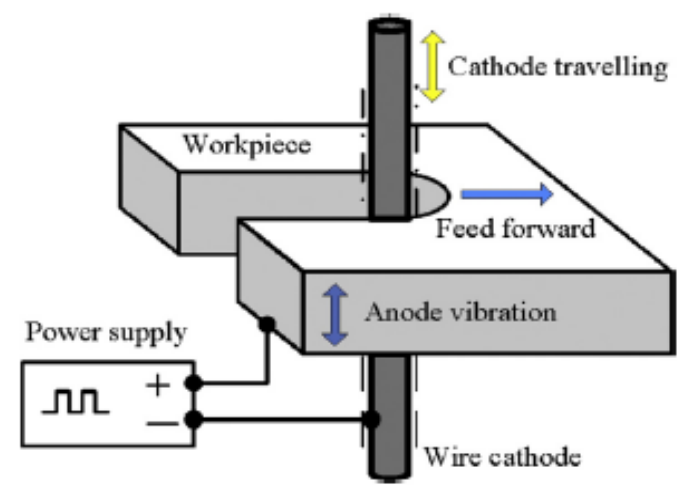

Fig. 19. Diagram of WECM machining in a plate with a thickness of $80 \mu \mathrm{m}$, made of a cobalt-based alloy with a titanium wire (Tungsten) with a diameter of $10 \mu \mathrm{m}$. Electrolyte $0.01 \mathrm{M} \mathrm{HCl}$. The wire and the workpiece make a vibrating motion, in addition, the wire is infed at $0.02 \mu \mathrm{m} / \mathrm{s}$ in the direction of the cut surface [25] 


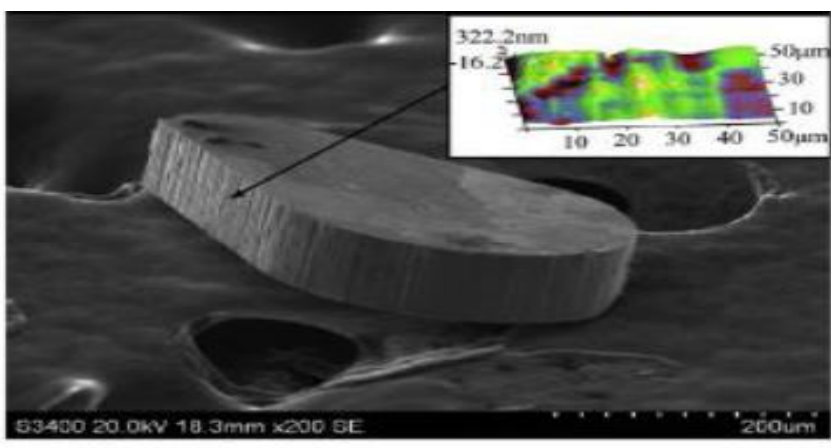

Fig. 20. Example of ECM cutting of a microelement with optimal parameters: anode vibrations with $5 \mu \mathrm{m}$ amplitude and $100 \mathrm{~Hz}$ frequency, $400 \mu \mathrm{m} / \mathrm{s}$ wire travel speed (for this shift, vibrations with $100 \mu \mathrm{m}$ amplitude and $5 \mathrm{~Hz}$ amplitude were applied), time of voltage pulse $40 \mathrm{~ns}$, pulse duration $6 \mu \mathrm{s}$. Dimensions of cut out elements: 150 and $400 \mu \mathrm{m}$. Cutting surface roughness $R a \approx$ $0.058 \mu \mathrm{m}[25]$

Fig. 21 presents a scheme for the production of microstructures applying the WECM method, although macrostructures or macroelements can also be produced in this way. Then, also removal of the dissolution products from the machined area is supported by a suitably selected relative movement of the electrodes (wire and workpiece), but in the considered case, a thicker wire than in previously described micro-cutting operations is used. In the case shown in fig. 21 , the removal of dissolving products from the machining area is supported by a special side surface structure of the wire (fig. 21 and fig. 23). This structure generates turbulent flow of electrolyte through the gap, which improves the removal efficiency of the reaction products and enables the cutting speed to be increased. The structuring of the side surface of the wire at WECM is a very important direction for further research.

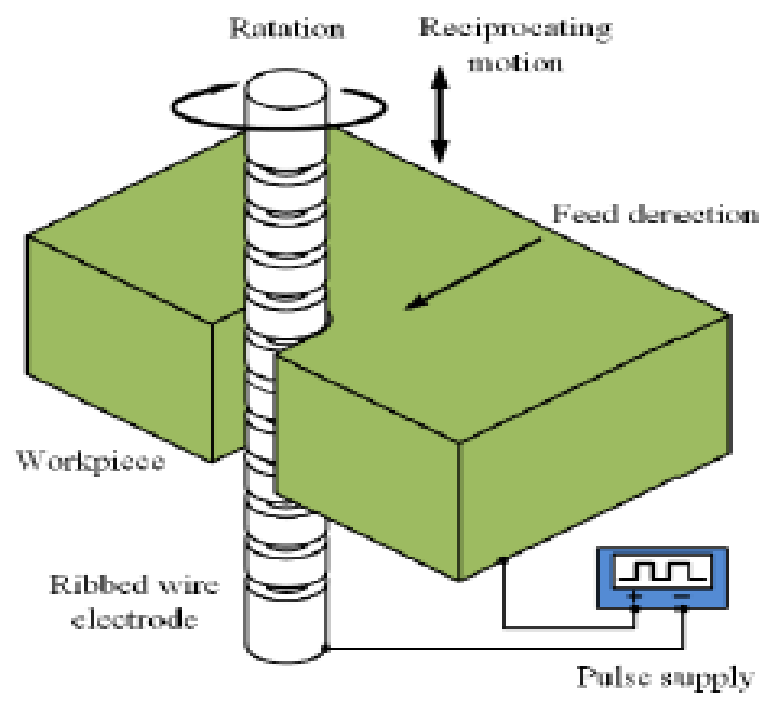

Fig. 21. Scheme of ECM cutting using a wire with a structured lateral surface [26]

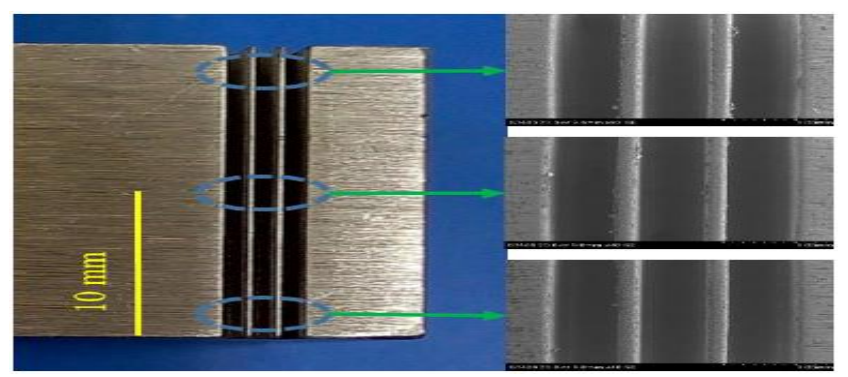

Fig. 22. Thin-wall microstructure (with a wall thickness of 230 $\mu \mathrm{m})$ made of a $20 \mathrm{~mm}$ thick stainless steel plate according to the diagram shown in fig. 21 and using the electrode shown in fig. 23. Amplitude of a $21 \mathrm{~V}$ pulse voltage, pulse frequency 100 $\mathrm{kHz}$, pulse duty factor $40 \%, \mathrm{NaNO}_{3}$ electrolyte $15 \mathrm{~g} / \mathrm{l}$, electrode (wire) feedrate $1 \mu \mathrm{m} / \mathrm{s}$, reverse movement amplitude $20 \mathrm{~mm}$, frequency $1.5 \mathrm{~Hz}$, wire rotational speed $5000 \mathrm{rpm}$ [26]

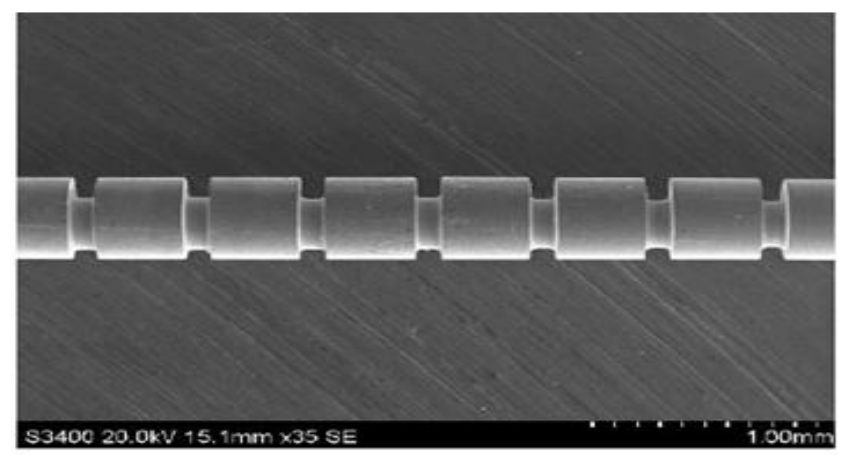

Fig. 23. Stainless steel wire electrode with a structured lateral surface: $500 \mu \mathrm{m}$ external diameter, medium width and depth of depressions - 113 and $100 \mu \mathrm{m}[26]$

Electrochemical wire cutting in micro and macro scale is intensively developed. This is evidenced by numerous publications [e.g. 25, 26, 27], from which it appears that this method is already used in the production of elements or structures with dimensions of approximately $100 \mu \mathrm{m}$.

\section{Conclusions}

Dynamic development of electrochemical treatment results from its basic advantages:

- material is removed as a result of electrochemical reactions - due to this, there are no mechanical forces and no changes in the structure of the surface layer; significant mechanical forces can act on the electrodes when machining large surfaces, being the result of electrolyte pressure;

- removing the material in small portions (atom by atom) enables obtaining a high surface quality, however, provided that optimal conditions for electrochemical dissolution and electrolyte flow are ensured;

- working electrode (cathode) does not wear - hydrogen is released at the cathode, which is then removed by electrolyte flowing through the processing area; the electrode wear can be reduced if there are discharges (fig. 2) caused by excessively high electrolyte temperature and hydrogen concentration.

Basic disadvantages of the ECM process and difficulties with its implementation result from its high complexity, including numerous physical and chemical phenomena occurring in the area of machining, which makes that mathematical modeling and computer simulations of this process is characterized by limited accuracy. In general, the ECM process is characterized by high randomness, and when electrolyte flow is not optimal, critical states may occur leading to electrical 
discharges that damage the working electrode and the workpiece, which is equivalent to interrupting the machining. For these reasons, the ECM process is extremely difficult to automate. The basic direction of the ECM process development is to increase the uniformity of the physical properties of the electrolyte distribution and the stability of its flow, as well as to minimize the possibility of electrical discharges. In practice, this amounts to:

- providing additional relative movement of the electrodes, which causes mixing of the electrolyte in the machining area and leveling of its properties; in particular, the use of ultrasonic vibrations, which intensify the occurrence of cavitation favoring the alignment of electrolyte properties and the de-passivation of the machined surface, is particularly effective;

- the use and thus the production of rotating elements using additional relative movements of the electrodes;

- supplying the gap with pulse voltage - often coupled with additional relative movement of electrodes (PECM);

- conducting the machining in pressure chambers with throttling of the electrolyte outflow - this results in the reduction of hydrogen volume concentration, stabilization of hydrodynamic conditions and good filling of the processing area;

- the use of universal electrodes and specially designed trajectories of relative workpiece movement (anodes) and tools (cathodes); in this case, the shape of the workpiece is obtained as a result of mapping the trajectory in the workpiece; the use of universal electrodes clearly reduces the processing area, stabilizes the electrolyte properties and reduces the probability of electrical discharges, and thus allows automation of the process (this type of machining is often called ECMCNC) - unfortunately, this is achieved at the expense of reduced machining efficiency.

Following directions of ECM process development emerge from above considerations:

- creation of integrated systems for modeling, simulation and design of technological processes and manufacturing (control programs for automatic implementation of the process on ECM-CNC machine tools);

- manufacture of turbine blades - although there are alternative technologies for turbine blades production, but they have not been implemented for reasons of flight safety - the ECM blades are of higher quality and it can be assumed that any changes in the shape of the blades or their surface structure will also be realized using ECM; - production of light and thin-walled elements (e.g. for aviation) from special hard-machinable materials - also composite ones;

- manufacture of microstructures and microelements of the MEMS type (micro-electro-mechanical-system);

- shaping special properties of the surface layer of cooperating elements (e.g. smoothing, production of bionic structures [28, 29]);

- further development of WECM;

- improvement of ECM technology and machine tools in traditional areas of ECM applications (aviation elements, tools for plastic processing, etc.).

\section{REFERENCES}

1. Davydov A.D., Kozak J. „Vysokoskorostnoe elektrochimiczeskoje formoobrazovanie". Moskwa: Izd. Nauka, 1990.

2. Dąbrowski L. „Podstawy komputerowej symulacji kształtowania elektrochemicznego". Prace Naukowe PW. Mechanika. 154 (1992).
3. Hardisty H., Milleham A.R., Shirvarni H. "A finite element simulation of the electrochemical machining process". CIRP Annals. 42, 1 (1993): pages 201-204.

4. Kozak J. "Mathematical models for computer simulation of electrochemical machining processes". Journal of Materials Processing Technology. 76, 1-3 (1998): pages 170-175.

5. Ruszaj A. "Niekonwencjonalne metody wytwarzania elementów maszyn i narzędzi" ("Unconventional methodes of machine parts and tools manufacturing"). Kraków, 1999, page 350.

6. Ruszaj A., Zybura M., Żurek R., Skrabalak G. "Some aspects of the electrochemical machining process supported by electrode ultrasonic vibration optimization". Proceedings of the Institution of Mechanical Engineers, Part B: Journal of Engineering Manufacture. 217 (2003): pages 1365-1371.

7. Ruszaj A., Czekaj J., Miller T., Skoczypiec S. "Electrochemical finishing surfaces after rough milling". International Journal for Manufacturing Science and Technology. 7, 2 (2005): page 21.

8. Kozak J., Chuchro M., Ruszaj A., Karbowski K. "The computer aided simulation of electrochemical process with universal spherical electrodes when machining sculptures surfaces". Journal of Materials Processing Technology. 107, 1 (2000): pages 283-287.

9. Hinduja S., Pattavanitch J. "Experimental and numerical investigations in electrochemical milling". CIRP Journal of Manufacturing Science and Technology. 12 (2016): pages 79-89.

10. Paczkowski T. „Symulacja komputerowa obróbki elektrochemicznej powierzchni krzywoliniowych elektrodą roboczą o złożonym ruchu translacyjnym" ("Computer simulation of electrochemical machining curvilinear surfaces using electrode tool with complex movement"). Bydgoszcz: Bydgoszcz University of Technology, 2012.

11. Sawicki J. „Analiza i modelowanie procesu obróbki elektrochemicznej krzywoliniowych powierzchni obrotowych" ("Analysis and modeling process of electrochemicaal machining of curvilinear rotary surfaces"). Bydgoszcz: Bydgoszcz University of Technology, 2013.

12. Tang L., Gan W.M. "Utilization of flow field simulations for cathode design in electrochemical machining of aerospace engine blisks channels". International Journal of Advanced Manufacturing Technology. 72 (2014): pages 1759-1766.

13. Dong Z.D. i in. "Cathode design investigation based on iterative correction of predicted profile errors in electrochemical machining of compressor blades". Chinese Journal of Aeronautics. January (2016).

14. Ruszaj A., Skoczypiec S., Gawlik J. "Special equipment and industrial applications of electrochemical machining process". Management and Production Engineering Review. 7, 2 (2016): pages 33-41.

15. Wijers J. "Upgrading to PEM". Mikroniek - Professional Journal on Precision Engineering. 54, 3 (2014): pages 48-53.

16. Klocke F. i in. "Turbomachinery component manufacture by application of electrochemical, electro-physical and photonic processes". CIRP Annals - Manufacturing Technology. 63 (2014): pages 703-726.

17. Domanowski P., Kozak J. "Direct and inverse problems of shaping by electrochemical generating machining". Journal of Material Processing Technology. 107 (2000): pages 300-306.

18. Ruszaj A. "Some aspects of electrochemical machining accuracy improvement". Proceedings INSECT 2016: International Symposium on Electrochemical Machining Technology VUB Vrije Universiteit Brussel. Faculty of Engineering. 2016, pages 29-35.

19. Volgin V.M., Lyubimov V.V., Davydov A.D. "Modelling and numerical simulation of electrochemical micromachining". Chemical Engineering Science. 140 (2016): s. 252-260.

20. Fan Z.-W., Hourng L.-W. "Electrochemical micro-drilling of deep holes by rotational cathode tools". International Journal of Advanced Manufacturing Technology. 52 (2011): pages 555563.

21. Schulze H.-P., Ruszaj A., Gmelin T., Kozak J., Karbowski K., Borkenhagen D., Leone M., Skoczypiec S. "Study of the process accuracy of the electrochemical micromachining using ultra nanosecond and short microsecond pulses". Proceedings 
of the 16th International Symposium on Electromachining. 2010, pages 651-656.

22. Choi S.H., Kim B.H. Shin H.S. Chung D.K., Chu C.N. "Analysis of electrochemical behaviors of WC-Co Alloy for micro ECM". Journal of Material Processing Technology. 213 (2013): pages 621-630.

23. Niu S., Qu N., Fu S., Fang X., Li H. "Investigation of inner jet electrochemical milling of nickel based Alloy GH4169/Inconel 718". International Journal of Manufacturing Technology. June (2017).

24. Bhattacharyya B., Munda J., Malapati M. "Advancement in electrochemical micro-machining". International Journal of Machine Tools \& Manufacture. 44 (2004): pages 1577-1589.

25. Xu K., Zeng Y., Li P., Zhu D. "Study of surface roughness in wire electrochemical micromachining". Journal of Materials Processing Technology. 222 (2015): pages 103-109.

26. Xianghe Z., Xiaolong F., Yongbin Z., Pengfei Z., Di Z. "In situ fabrication of ribbed wire electrodes for wire electrochemical micromachining". International Journal of Electrochemical Science. 11 (2016): pages 2335-2344.

27. Zeng Y., Yu Q., Fang X., Xu K., Li H., Qu H. "Wire electrochemical machining with monodirectional travelling wire". International Journal of Advanced Manufacturing Technology. Published online 07.01.2015.

28. Ruszaj A. „Bionika w rozwoju inżynierii produkcji” ("Bionic in production engineering development"). Mechanik. 5-6 (2016): pages 350-355.

29. Ruszaj A. "Bionic impact on industrial production development". Advances in Manufacturing Science and Technology. 39, 4 (2015): pages 5-22 